\title{
Under Moodle Stage Apply Constructivist “3B” Reading Teaching Methods \\ to Chinese High School Students
}

\author{
Lei Shi, Zhanyi He \\ Chang chun University of Chinese Medicine
}

Key words: “3B” teaching theory; teaching methods; Moodle stage

\begin{abstract}
Moodle stage is more convenient to teach English. Under this effective facility, constructivist "3B" teaching theory is going to be more efficient to improve Chinese students'English learning level. The passage states several methods to improve their reading ability.

In China, English is learned as a foreign language and face-to-face communication with native speakers of English is still largely confined for high school students. Thus English reading provides the most efficient and hence the most important channel of linguistic input through which students improve their communicative competence.
\end{abstract}

\section{Present situation of Chinese high school students}

In the high school class of China, mostly the text is translated word by word and sentence by sentence. Readers passively absorb what the writer has produced during the process of reading. Consequently, students have little chance of practicing listening and speaking in the class. Much of the time in class is occupied by teachers to explain language rules rather than oral communication in target language.

\section{How to enhance the reading competence of high school students in order to get high marks?}

How does Moodle stage work for reading?

With the fast development of computer and internet facilities, education methods also make great progress. They are more convenient and effective. Such as flipping class which depends on internet and modern techniques make our teaching more convenient and efficient. Moodle stage also is widely used in flippingclass, which can provide several functions. First, it can store PPT, learning materials, teaching videos etc. second, it can give marks to the reading jobs of students who hand in their tasks and give an analysis of the whole class. It also can tell which question is answered worst or best. Third, students can hand in homework in this stage. At last, it's very convenient for the communication between students and students and teacher.

What is the Constructivist Views of Reading?

Constructivists reading as a process in which the reader actively decodes meaningmaterials. Readers should actively involve in the text. The reader actually constructs the meaning he or she arrives at.

\section{Constructivist “3B” Teaching Theory}

The first one is that students are the most important factor that determines the outcome of FLT and FL learning, which can be termed figuratively and briefly as the theory of 'big students'. The second one is that English as foreign language can be acquired and taught in the socialized big class rather than only in the closed school or classrooms, which can be termed figuratively and briefly as the theory of 'big classes'. The third one is that English can be acquired and taught well by adequate teaching materials that are at similar level and different kinds, which can be termed figuratively and briefly as the theory of 'big teaching materials'. 
Constructivist “3B” Reading Teaching Methods

\section{How to Utilize "Big students" Idea in Reading Teaching?}

Students are the center of learning. Improving the integrating skills of reading should start from the stimulating of the students' interest in reading. A strong desire to learn can make learning outstandingly efficient (Harmer, J., 2000).

Increase the intuition and vividness character of reading materials through the Moodle stage.

It's said by scientists that students are easier to learn language with all the organs together, that's to say the stimulation of pictures, voice which are helpful to learn language. Consequently, teachers should make use all kinds of teaching tools to raise the curiosity to read the reading materials to read automatically, such as diagrams,flipping classes, pictures, andPower Points, which can be stored on the Moodle stage and easily obtained by the students.

Utilize the differences of cultures between countries to arouse their interest.

The great part of constructivism is to emphasize the original knowledge of the readers which are composed of language knowledge and background knowledge. So background knowledge which includes culture is worth noticing. The reason that Chinese students are not good at reading comprehension is due to the differences in culture.

As we know, culture is useful in reading and there are different cultures between the east and the west. Consequently, teachers should introduce the culture of the reading materials which is on the one hand help students to construct their reading structure easily and on the other hand stimulate their interest.

Promote "competition system" to stimulate their reading.

Teachers can promote "competition system” in order to let more students join in reading actively. The behaviors are as following:

1).Report the amount of their reading after class to classmates, ands take turn to tell the main idea that he has read. 2). Hold a reading speed contest. 3). Praise the one who read more and are faster in reading.

Count on the way of output---English Conner to induce them to read more.

English corner is a good place for students to use what they learn from reading materials, because every student will be eager to find a meaningful and realistic topic to show their knowledge. After coming back, the listeners will try to probe topic if they don't know. So it will stimulate their reading interest.

Ask questions by students themselves to encourage reading

Constructivist "3B" method advocates that students are the centre of learning a foreign language. So it's a good way to lead students to probe and think out questions to ask the rest of students in order to check it. For example, some students see the articles from their own point of view, so through asking questions by themselves to more excellent models and peers, they can solve the misunderstanding by themselves, which is easier to handle. Thus by asking and answering between students about the materials that they are reading, they can solve the puzzle and increase their interests. b. How to Utilize "Big class" Idea in Reading Teaching?

It has been demonstrated that it's hard to learn English well for most students in the condition of Chinese common school within several hours per week. Consequently, it's instinct necessary for the students to improve reading ability in and out of the classroom.

Thus the students will have a larger "class" where they can meet more people, know more people and make acquaintance with them, talk about anything they are interested in in English with them, exchange some messages, emotions with them or do something or play with the FL with them to enjoy themselves.

1. Conduct a colorful and interesting "lead in" with the help of the Moodle stage before class. 
Teachers can induce the students to read the text actively through a successful "lead in", such as questioning, relative voice materials, TV show, PowerPoint which could be stored in the Moodle stage before the class and give assignment to students.

A good and effective lead in remark usually has these qualities:

1).It makes the students want to read the text.

2). It helps the students to relate the text to their own experience, aims, and interests.

3). It involves the students actively, for example by means of questions or discussion.

4). It does not tell the students anything they can find out by reading the text.

5). It is usually short.(Nuttall, 2002)

On the other hand, after a good preparation, they are also eager to join in the warming up process, their speeches and activities also will enlighten and stimulate others to read more carefully in order to check whether what the speakers said is correct. Thus, all of them will devote in reading more enthusiastically.

2. Utilize socialized class to improve reading ability---read out of class.

Besides reading activities in the class, we need require students to do pre-activities and post-activities on reading. That is to tell the background information of the reading material preciously, and give them time to prepare it by looking up the books, surfing on the line etc. before next class. At the same time, tell them what level they need to reach about the text. That is to master the relative information and knowledge previously, automatically and broadly. Such as when we learn about unit4 《Global Warming》 in book 5. It's a topic close to our daily life, so teachers can give task preciously and leave enough time for the students to gather the relative information by themselves. Owing to curiosity and the desire to show their knowledge to the classmates and teachers, they will read more relative materials about the global warming out of class.

3. Emphasize the reading activities out of the class

Do lots of extensive reading out of class can improve the reading speed, so more interesting materials can be covered which enable the readers to have a sense of enjoyment and achievement often that is not found in intensive reading. Senior high school is golden time to direct students do reading outside of class, because they need to master fairly large vocabulary and the basic grammatical items to cope with reading comprehension.

4. Retell the reading materials with fluent oral English after class.

Some reading materials are essential which contain varieties of language points, important words, complex sentence structures and good rhetoric. Only through reciting these essences can a student improve his language ability which can guarantee their reading. A good way to do it is to give them chances to show their jobs in the presence of the whole class and teachers.

5. Use output to help students realize the necessity of reading---writing

It's beneficial to ask students to write reading summaries after they read a story or essay. Because writing is an effective output way, through which students can sense what are their shortcomings and they will feel there is a long way to go in order to be a good reader, so sometimes they will reread the materials.

\section{How to Utilize "Big material" Idea in Reading Teaching?}

Constructivist “ $3 \mathrm{~B}$ ” reading methods advocate the reading input should have different levels and be extended to various kinds of materials, whose degree of difficulty should be appropriate to their originate level which means "a little" higher exactly.

Of course it also includes the English materials from the TV, radio, films, dramas, newspapers, magazines and the songs, etc.

Choose the materials with the proper degree of difficulty

According to $\mathrm{i}+1$ theory, constructivist " $3 \mathrm{~B}$ " theory advocates that the difficulty of the reading materials should be higher than the students' reading capacity, but it's still reachable with the guide of teachers and their struggles. In detail, the vocabulary they master for senior 2 is about 2000-2800, so the teaching materials should not be too difficult and the number of the new words in 
the reading materials should not be too high.

Nowadays, the Moodle stage can provide many kinds of English reading materials according to the students'originalEnglish level and account the number of words that students have already mastered. At the same time, provide the passage which is suit for the students.

Pay attention to listening materials

According to the Input Hypothesis by Krashen "all that the language learners need to do is to contact with large amounts of understandable input and the task of teachers is just to offer the input, lower the anxiety and improve their confidence, so the language will be acquired naturally.”Only these process__ input---intake---output can students do a good job in learning language and there are only to accesses of input, one is reading and the other is listening.

Teachers can broadcast various listening materials such as the recording of the text, VOA, $\mathrm{BBC}$, which accompany with the reading materials.

\section{Conclusion}

With the help of the Moodle stage, these constructivist “3B" reading teaching methods will be very effective in improving Chinese high school students' reading ability.

\section{References}

[1]Davis (Eds.), The Social Construction of the person.NewYork: Springer-Verlag.

[2]Goodman, K. S. (1967). Reading: A Psycholinguistic Guessing Game. In Gollasch, F. (ed.) Language and Literacy, 33-34.

[3 ]Nuttall, Christine. 1982 teaching reading skills in a foreign language, Heinermann Educational Books, Ltd. Landon

[4]Ormrod, J. 1995. Educational Psychology: principles and Applications [M]. Englewood cliffs, NJ Prendce-Hall.

[5]Piaget, J. 1974. To Understand is to Invent. New York: Viking Press.Penrose,A. and Geisler C. (1994). Writing Communication . 